\title{
How consistent are lordosis, range of movement and lumbo-pelvic rhythm in people with and without back pain?
}

\author{
Robert A. Laird ${ }^{1,4^{*}}$, Peter Kent ${ }^{2,3}$ and Jennifer L. Keating ${ }^{1}$
}

\begin{abstract}
Background: Comparing movements/postures in people with and without lower back pain (LBP) may assist identifying LBP-specific dysfunction and its relationship to pain or activity limitation. This study compared the consistency in lumbo-pelvic posture and movement (range and pattern) in people with and without chronic LBP (>12 week's duration).
\end{abstract}

Methods: Wireless, wearable, inertial measurement units measured lumbar lordosis angle, range of movement (ROM) and lumbo-pelvic rhythm in adults $(n=63)$. Measurements were taken on three separate occasions: two tests on the same day with different raters and a third (intra-rater) test one to two weeks later. Participants performed five repetitions of tested postures or movements. Test data were captured automatically. Minimal detectable change scores $\left(\mathrm{MDC}_{90}\right)$ provided estimates of between-test consistency.

Results: There was no significant difference between participants with and without LBP for lordosis angle. There were significant differences for pelvic flexion ROM (LBP 60.8 , NoLBP 54.8 $, F(1,63)=4.31, p=0.04)$, lumbar right lateral flexion ROM (LBP 22.2 $2^{\circ}$, NoLBP $\left.24.6^{\circ} \mathrm{F}(1,63)=4.48, p=.04\right)$, trunk right lateral flexion ROM (LBP 28.4 ${ }^{\circ}$, NoLBP $\left.31.7^{\circ}, F(1,63)=5.9, p=.02\right)$ and lumbar contribution to lumbo-pelvic rhythm in the LBP group (LBP $45.8 \%, F(1,63)$ $=4.20$, NoLBP $51.3 \% p=.044)$. MDC 90 estimates for intra and inter-rater comparisons were $10^{\circ}-15^{\circ}$ for lumbar lordosis, and $5^{\circ}-15^{\circ}$ for most ROM. For lumbo-pelvic rhythm, we found $8-15 \%$ variation in lumbar contribution to flexion and lateral flexion and $36-56 \%$ variation in extension. Good to excellent agreement (reliability) was seen between raters (mean $r=.88$, ICC $(2,2)$ ).

Conclusion: Comparisons of ROM between people with and without LBP showed few differences between groups, with reduced relative lumbar contribution to trunk flexion. There was no difference between groups for lordosis. Wide, within-group differences were seen for both groups for ROM and lordosis. Due to variability between test occasions, changes would need to exceed $10^{\circ}-15^{\circ}$ for lumbar lordosis, $5^{\circ}-15^{\circ}$ for ROM components, and $8-15 \%$ of lumbar contribution to lumbo-pelvic rhythm, to have $90 \%$ confidence that movements had actually changed. Lordosis, range of movement and lumbo-pelvic rhythm typically demonstrate variability between same-day and different-day tests. This variability needs to be considered when interpreting posture and movement changes.

Keywords: Low back pain, Movement disorders, Posture, ROM, Lordosis, Lumbo-pelvic rhythm, Reliability

\footnotetext{
* Correspondence: robert.laird@monash.edu

${ }^{1}$ Department of Physiotherapy, Monash University, PO Box 527, Frankston,

VIC 3199, Australia

${ }^{4} 380$ Springvale Rd, Forest Hill, 3131 Melbourne, VIC, Australia

Full list of author information is available at the end of the article
} 


\section{Background}

In a recent 'Global Burden of Disease Study' [1], low back pain (LBP) was rated as the health condition responsible for the most years lived with disability when all common diseases were considered. Despite considerable research efforts, it is still unclear why some people recover from LBP pain and others do not, or how to match available interventions to careseekers [2]. Many studies have focused on movement irregularities and patterns in LBP. Movement range has been used to monitor recovery status following interventions, and various patterns of movement have been investigated, including lumbar versus pelvic (hip) contribution to trunk movement (often called lumbo-pelvic rhythm) [3-9]. Opinions vary regarding the utility of measuring movement range and patterns. Nevertheless, many non-invasive interventions continue to target movement dysfunction in people with LBP.

A concept with current support is that individuals have consistent, and therefore recognisable, patterns of posture and movement, which may contribute to ongoing LBP [10-13]. Movement patterns such as excessive end range lumbar movements or postures [14], excessive or reduced lumbar contribution to trunk flexion [15], trunk rigidity [16], loss of flexion relaxation response [17], and reduced proprioception $[18,19]$, amongst others, have been linked to LBP. Recent research supports the concept that individualised approaches to modification of posture and movement patterns might reduce LBP $[20,21]$. However, the relationship between specific movement characteristics/ postures and LBP remains unclear. A recent systematic review of common movement characteristics in people with and without LBP concluded that people with LBP typically have reduced range of lumbar spine movement, move more slowly and have reduced proprioception compared to people without LBP [22]. Another recent review found only limited evidence for identifying and monitoring changes to movement patterns or postures [23].

Aberrant movement (range or patterns) and/or postures associated with LBP might be identifiable, provided these movements were consistent and could be accurately measured. Of particular clinical interest is the consistency of an individual's typical movement over short time periods (e.g., within a clinical session on the same day) and over longer time periods (e.g., 1 to 2 weeks apart). Common therapeutic targets of 'improving posture' and normalising dysfunctional movements are often influenced by within-session or between-session changes in movements following a treatment. Therefore, knowledge of the kinematic stability of movement patterns both within and between treatment sessions is important to clinicians who aim to identify, label and treat movement 'dysfunctions'. If movement/postural patterns normally fluctuate, and the variance in measures of movement/posture can be quantified, measurements outside the range of expected variation are likely to represent true movement alteration/adaptation. Those adaptive movements could be used to quantify response to treatment or to identify movements that either trigger, or are a response to, LBP.

Investigating the associations between movement and pain has been limited by difficulty in measuring and monitoring typical movement/posture both within clinical settings and in normal daily activity. Technological advances with movement sensors have enabled new opportunities to investigate the relationship between movement and pain [24-26]. These devices are skin surface-mounted and generate data on lumbo-pelvic movements and postures, such as angle, timing, position and concurrent surface electromyography. There is preliminary evidence of high levels of accuracy relative to laboratory based opto-electronic measurement systems and they appear to have sufficient accuracy for clinical applications [24, 27].

This study investigated and compared consistency in lumbo-pelvic posture and movement (range and pattern) in people with and without chronic LBP ( $>12$ week's duration). We examined the consistency (repeatability/ measurement stability) of three types of lumbo-pelvic kinematic characteristics: (i) the postural characteristic of lordosis, (ii) range of movement (ROM) of flexion, extension, and lateral flexion, and (iii) lumbar compared to pelvic contributions to movement (lumbo-pelvic rhythm). Three types of movement consistency were of interest: 1) the consistency demonstrated when an individual repeats the same movement within a single test, 2) the consistency demonstrated when a person is tested twice by two different raters on the same day, and 3) the consistency demonstrated when a person has a repeated test by the same person 7-14 days after the first test.

\section{Methods}

Study selection: inclusion and exclusion criteria

Participants (with and without LBP) were recruited by poster and word-of-mouth advertising from private physiotherapy clinics and a university. People with LBP (LBP group) were included if they had back $+/-$ leg pain for $>$ 12 weeks and a pain score of $>2$ on a 0 to 10 Numerical Rating Scale (average of worst, current, usual pain intensity) [28]. Exclusion criteria were any of the following: (i) previous lumbar surgery, (ii) any invasive spinal procedures for LBP, including therapeutic injections, within the last 12 months, (iii) pregnancy (iv) neoplasm, infection, fracture, inflammatory disease, neurological disease or any metabolic disorder that had the potential to affect the lumbo-pelvic region, (v) implanted electrical medical device, (vi) any medical abnormalities or conditions 
(e.g., knee or hip conditions) that in the opinion of the clinician would substantively interfere with an ability to participate in the study, (vii) a known allergic skin reaction to adhesive tapes or plasters, or (viii) $\mathrm{BMI}>30$ (where it becomes difficult to palpate bony landmarks). Participants recruited into the sample without back pain (NoLBP group) were excluded if they had (i) back pain at the time of testing, (ii) an episode of back pain that had necessitated attending a medical practitioner or allied health professional in the last 12 months, (iii) time off work due to back pain in the last 12 months or, (iv) any back pain during or between testing procedures. All potential participants were screened for suitability by a trained administrator, by direct contact and follow-up phone call if clarification was required, and then invited to participate. Ethics approval was obtained from Monash University (approval numberCF12/ 1995-20 12001090). All participants gave written informed consent.

\section{Measurement protocol}

Figure 1 presents the test procedures. Each participant was tested on two separate days. On the first test day, they were tested twice (Test 1 and Test 2) by two different raters (Raters A and B). On the second test day, they were assessed once (Test 3) by Rater A. On each test occasion, participants were assessed while they performed five repetitions of each movement. Data were collected at two geographic locations by physiotherapists with a minimum of 2 years' clinical experience.

To standardise the testing procedures, $3 \mathrm{~h}$ of practice for standardised palpation of bony landmarks, sensor placement and measurement procedures preceded the initial data collection. Standardised instructions were used by both raters with pre-determined verbal cues for each movement test. Rater order (i.e., who administered Tests 1 or 2) was randomised pragmatically by rater availability. Participants were tested in the same room for all tests, and where possible, were tested at a similar time of day.

All kinematic data were automatically captured by the ViMove system independently of actions by the rater.

\section{Equipment}

The ViMove system (DorsaVi, Australia) is an inertial measurement system comprised of two wireless movement sensors containing a triaxial accelerometer, a triaxial gyroscope and a magnetometer, two wireless surface electromyography (EMG) sensors (these EMG data were not reported in this paper), and a small wireless recording device that can be easily carried (e.g., in a pocket). The manufacturer reports average differences of $<1^{\circ}$ for single plane, through-range movements when comparing matched measurements from the ViMove and a Fastrak opto-electronic device [29]. The ViMove movement sensors collect data at approximately $20 \mathrm{~Hz}$.

\section{Test procedures}

Participants were partially undressed to expose the body from T12 to the posterior superior iliac spines (PSIS) (see Fig. 2). Shoes were removed. The upper border of each PSIS was palpated and marked by Rater 1. To standardise sensor placement, the distance from the PSIS marker to the floor was recorded using a rigid vertical ruler and right-angled square. These measurements were used to replicate PSIS markings in subsequent testing [30]. A plastic template (part of the ViMove system) for standardising relative sensor placement was then aligned to the marking on the PSIS and used to guide sensor attachments. Movement sensors were attached to the skin over the T12 and S2 spinous processes using disposable adhesive pads. Movements were then demonstrated by the rater, after which participants were instructed to move through a standardised sequence of movements (summarised in Additional file 1).

During these movements, data on lumbo-pelvic angles and ROM were recorded automatically by the device. The only role of the rater was to request the required movement in the required sequence and initiate the data collection process. On completion of a test, sensors and adhesive pads were removed and the skin was wiped clean. Participants rested for $5 \mathrm{~min}$ then the entire procedure was immediately repeated by a second rater. Each rater was blind to data collected by the other rater

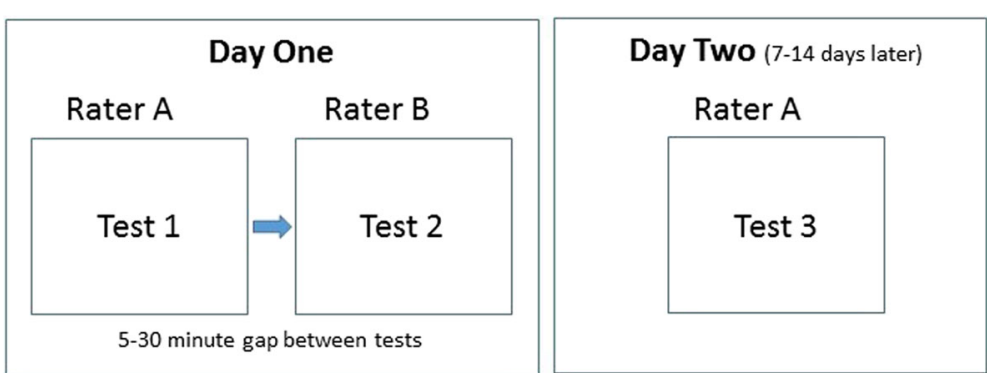

Fig. 1 Flow diagram of assessment procedures 


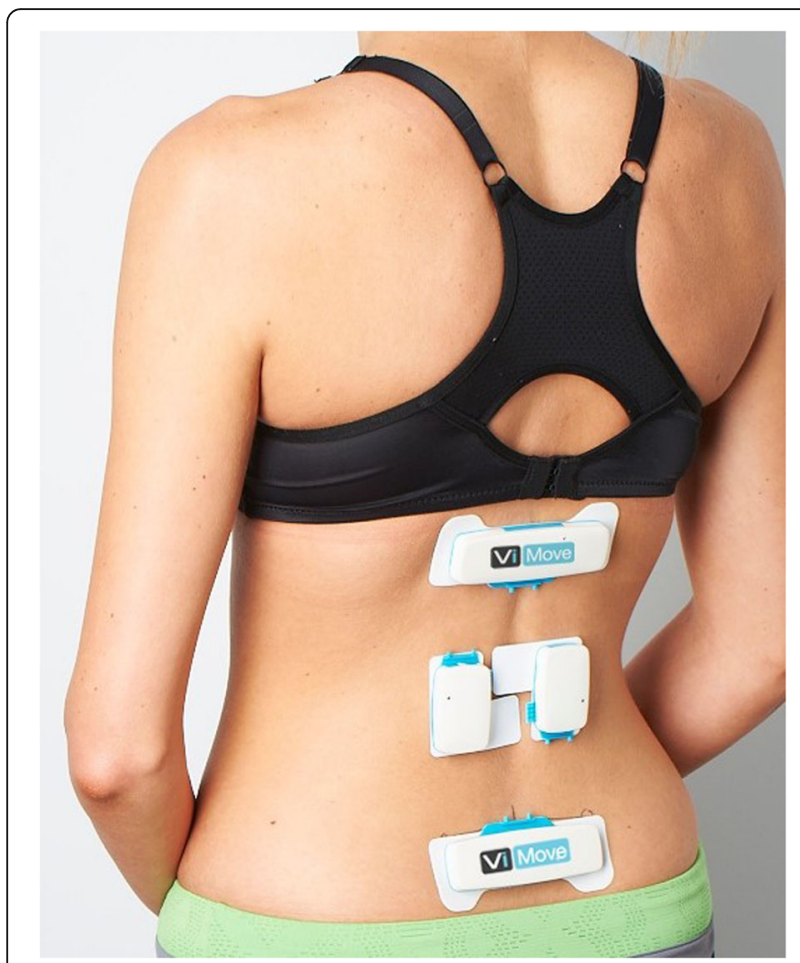

Fig. 2 Placement of the ViMove sensors

more are likely to assume a normal distribution and thereby provide more adequate data for parametric tests.

\section{Data analysis}

Data on body position were sampled and recorded at approximately $20 \mathrm{~Hz}$ for each of the five repetitions of flexion, extension and left and right lateral flexion movements. Averaged lumbar lordosis angle was recorded in standing over a 5 -s period.

Peak angles were calculated for trunk and pelvic sensors to indicate maximum angular displacement at T12 (trunk movement) and S2 (pelvic/hip movement). Lumbar movement (movement between T12 to S2) was calculated by subtracting pelvic movement (movement of the lower sensor at S2) from trunk movement (movement of the upper sensor at T12). In addition to static posture and ROM, data on 'lumbar versus pelvic' contribution to flexion, extension and lateral flexion were collected during each movement. This is shown graphically in Fig. 3. A summary measure of this pattern of lumbar versus pelvic contribution to trunk movement (lumbo-pelvic rhythm) was estimated by calculating the percentage contribution of lumbar ROM to peak trunk ROM for flexion, extension and lateral flexion.

\section{Statistical analysis}

Participant demographics (gender, BMI, pain and activity limitations) were summarised.

distance of the PSIS from the floor. Participants then returned 7-14 days later for a repeat assessment (Test 3) by Rater A. For participants with LBP, pain was recorded using three Numerical Rating Scales (worst pain $=10$, no pain $=0$ ), and the average of current, usual and worst pain over the previous 2 weeks was used [31]). Activity limitation was assessed using the Roland Morris Disability Questionnaire [32]. Pain and activity limitation were recorded on both assessment occasions.

\section{Sample size}

No existing data were available to inform sample size estimates. A sample of 60 adults aged 18-60 years $(n=$ 30 with LBP, $n=30$ without LBP) were recruited. This sample size would allow detection of a correlation of 0.44 or more between repeated measures in each group of 30, with an alpha of 0.05 and power of 0.8 [33]. Arbitrarily, we assumed this was an adequate threshold, as movement consistency that resulted in lower retest correlations would provide adequate evidence that the individual variations in movement patterns would be so large that patterns of movements would be too variable to be clinically interpretable. In addition, a sample size of 30 is recommended where researchers are studying differences between two sets of scores, as difference scores for samples of 30 or

\section{Comparing ROM for participants with and without LBP} Mean ROM scores for each of the repetitions (three tests each of five repetitions) for each movement, for LBP and NoLBP participants, were tested for differences between groups using a repeated measures ANOVA.

\section{Consistency in repeated measurements}

To examine the overall consistency in repeated movements, the standard deviation of all measurements of a movement for each participant was calculated. Differences in standard deviations between groups were tested using independent t-tests.

\section{Within-test repeated movement consistency}

Each of the three tests consisted of five repetitions for each movement. We considered that the best estimate of a person's ROM would most likely be an average of repeated measurements. Before commencing analysis of the magnitude of error in movement estimates, the five repetitions for Test 1 were examined to determine whether any of the repetitions were systematically different from others. Systematic variation for specific repetitions was assessed using a paired $t$-test to compare the mean for the first repetition to the mean for each of the other 


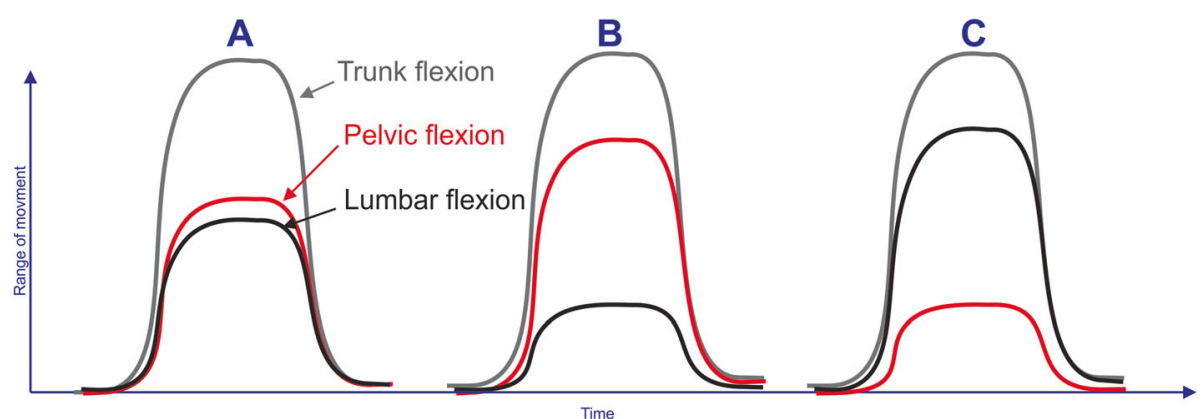

Fig. 3 Examples of lumbo-pelvic rhythm movement patterns for flexion. $R O M=R O M$; Trunk flexion $R O M=g r e y$ line, pelvic (hip) flexion $\mathrm{ROM}=$ red line, and lumbar flexion ROM = black line. Peak trunk flexion angles, recorded with the T12 sensor, consist of two components: (1) pelvic (pelvis-on-hip) movement and (2) lumbar movement. a Typical flexion movement pattern of slightly greater pelvic compared to lumbar contribution to trunk movement. b Stiff lumbar spine with small lumbar contribution and mostly pelvic movement contributing to trunk flexion. c Greater lumbar and relatively smaller pelvic movement

repetitions; this was repeated for repetitions $2,3,4$ and 5 , for each movement, and for LBP and NoLBP participants separately. Based on this analysis, we made decisions regarding the repetitions that were suitable for inclusion in subsequent analyses.

\section{Movement consistency between tests on the same day (inter-rater reliability)}

The average of stable repetitions was used as best evidence of the typical movement for each participant. Consistency between repeated tests was estimated using the two-way, random effects, absolute agreement between two raters, Intraclass Correlation Coefficient (ICC 2, 2) statistic. The magnitude of differences between repeated tests was summarised using Bland-Altman plots with $95 \%$ limits of agreement (LOA) and the minimal detectable change $\left(\mathrm{MDC}_{90}\right)$ statistic. These were calculated using the standard deviation of the differences between repeated tests multiplied by 1.65 for the $\mathrm{MDC}_{90}$ and 1.96 for $95 \%$ confidence levels (LOA). The $\mathrm{MDC}_{90}$ metric with its $90 \% \mathrm{CI}$ balances statistical rigour with clinical utility in deciphering changes in measurements.

\section{Movement consistency between tests on different days (7-14 days after the first test: intra-rater reliability)}

Methods used to calculate the consistency of measurements taken on the same day were repeated for measurements taken on two test occasions 7-14 days apart. The conceptual framework and definitions of reliability used in this study were those published by the COSMIN group [34]. All analyses were performed using a statistical software package (STATA, version 12).

\section{Results}

\section{Demographics}

Participant gender, age, BMI, LBP intensity and activity limitation are presented in Table 1. There was a significant difference between groups in age. People with LBP were, on average, 10.3 years older than people without LBP.

\section{Comparing ROM for participants with and without LBP}

Peak ROM scores for movement repetition are illustrated in Fig. 4 and detailed in Table 2. Despite the typical differences in mean scores between LBP and NoLBP participants, these were significant only for pelvic ROM in flexion (LBP $60.8^{\circ}$, NoLBP $\left.54.8^{\circ}, \mathrm{F}(1,63)=4.31, p=0.04\right)$, lumbar ROM in right lateral flexion (LBP $22.2^{\circ}$, NoLBP $24.6^{\circ}$ $\mathrm{F}(1,63)=4.48, p=.04$ and trunk $\mathrm{ROM}$ in right lateral flexion (LBP 28.4 $4^{\circ}$ NoLBP $31.7^{\circ}, \mathrm{F}(1,63)=5.9, p=.02$ ).

\section{Consistency in repeated measurements}

There were no significant differences between LBP and NoLBP participants in consistency of the 15 repetitions of each movement (5 repetitions $\times 3$ tests) with the exception of trunk movement during right lateral

Table 1 Participant demographics

\begin{tabular}{|c|c|c|c|c|c|c|}
\hline & Number & Gender (\% female) & BMI $\left(\mathrm{kg} / \mathrm{m}^{2}\right)$ & Age (years) & Pain (0-10 scale) & Activity limitation (RMDQ 24) \\
\hline NoLBP group & 32 & $42 \%$ & $24.4 \pm 3.1$ & $35.5^{a} \pm 12.4$ & No pain & No activity limitation \\
\hline LBP group (Test 1) & 30 & $50 \%$ & $24.1 \pm 5.6$ & $45.8 \pm 11.6$ & $4.5 \pm 1.3$ & $6.2 \pm 3.5$ \\
\hline LBP group (Test 3) & & & & & $4.5 \pm 1.3$ & $4.7 \pm 2.6^{b}$ \\
\hline
\end{tabular}

All numbers indicate mean \pm standard deviation

a Significant difference in age between groups, $p=.001$

${ }^{\mathrm{b}}$ Significant difference for activity limitation between Test 1 versus Test 3 in the LBP group 


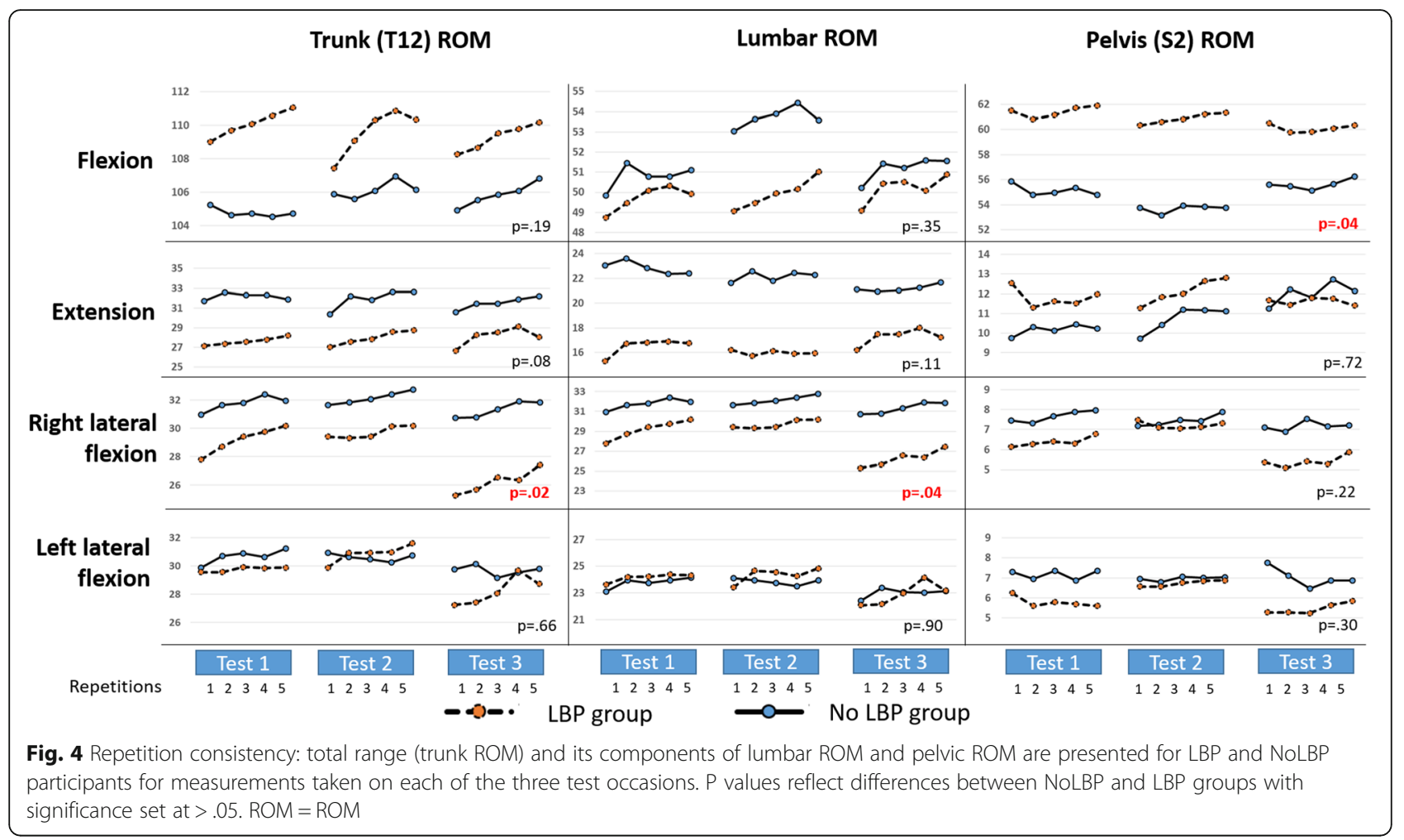

flexion, where the standard deviation was significantly greater for the LBP group $\left(2.7^{\circ} \pm .25^{\circ}\right)$ compared to the NoLBP group $\left(1.98^{\circ} \pm .14^{\circ}\right)$.

\section{Within-test repeated movement consistency}

On examination of pairwise comparisons of repetitions 1 to 5 , little evidence was found of significant effects attributable to repetition. Exceptions were lumbar flexion, and right lateral flexion (trunk and lumbar ROM) where (typically for both groups) ROM for the first repetition exhibited significantly smaller ROM than all other repetitions. Figure 4 shows similar patterns when other movements were considered. Consequently, repetition one was removed from subsequent analyses.

\section{Movement consistency between tests Lordosis and ROM}

Table 2 summarises data for lordosis and ROM. Mean lordosis angles (across all three tests) for the two groups were not significantly different: $30.1^{\circ} \pm 11.1^{\circ}$ for the NoLBP group and $27.8^{\circ} \pm 11.2^{\circ}$ for the LBP group. The minimal detectable change based on the middle $90 \%$ of scores $\left(\mathrm{MDC}_{90}\right)$ for measurements of lordosis taken on the same day was $\pm 11.3^{\circ}$ for the NoLBP group and $\pm 8.8^{\circ}$ for the LBP group, and approximately $\pm 15^{\circ}$ (both groups) for different-day comparisons.
Different-day measurements generally showed greater inconsistency than measurements taken on the same day. For example, trunk flexion for the LBP group would have to change by more than $\pm 8.7^{\circ}\left(\mathrm{MDC}_{90}\right)$ between tests on the same day for $90 \%$ confidence that observed changes were not due to typical variation in these measurements. This increases to $\pm 10.2^{\circ}$ change for tests on different days. An example of Bland Altman plots displaying the limits of agreement (95\% confidence intervals), for flexion, can be seen in Fig. 5. Trunk ROM measurement consistently showed greater stability compared to lumbar or pelvic ROM measurements for same-day and different-day comparisons. For example, for the LBP group, the $\mathrm{MDC}_{90}$ of trunk flexion for different-day tests was $10.2^{\circ}$, compared to an $\mathrm{MDC}_{90}$ of $17^{\circ}$ for lumbar $\mathrm{ROM}$, and an $\mathrm{MDC}_{90}$ of $19^{\circ}$ for pelvic ROM.

\section{Lumbo-pelvic rhythm}

Table 3 summarises the percentage contribution of lumbar ROM to trunk ROM (lumbo-pelvic rhythm). A significant difference between groups was seen for flexion (NoLBP $51.3 \% \pm 9.4 \%$, LBP $45.8 \% \pm 8.6 \%$, $\mathrm{F}(1,63)=4.20, p=.0445)$. $\mathrm{MDC}_{90}$ scores for lumbo-pelvic rhythm suggest changes of relative lumbar versus pelvic contribution to trunk movement of between 9 and 15\% would, for $90 \%$ of tests, indicate true change for flexion and lateral flexion, while changes between 36 and $56 \%$ 
Table 2 Lordosis and ROM scores, and consistency between tests (degrees)

\begin{tabular}{|c|c|c|c|c|c|c|c|c|c|c|}
\hline \multirow[t]{2}{*}{ Movement } & \multirow[t]{2}{*}{ Region } & \multirow[t]{2}{*}{ Back pain status } & \multicolumn{4}{|l|}{$\mathrm{ROM}^{\mathrm{a}}$} & \multicolumn{2}{|c|}{$\begin{array}{l}\text { Inter-rater agreement } \\
\text { (same-day, different raters) } \\
\text { Test } 1 \text { versus Test } 2\end{array}$} & \multicolumn{2}{|l|}{$\begin{array}{l}\text { Intra-rater agreement } \\
\text { (different-days, same rater) } \\
\text { Test } 1 \text { versus Test } 3\end{array}$} \\
\hline & & & Test 1 & Test 2 & Test 3 & $\begin{array}{l}\text { Average for } \\
\text { all } 3 \text { Tests }\end{array}$ & $\begin{array}{l}\text { Mean \& SD of } \\
\text { differences } \\
\text { between Test } 1 \& \\
\text { Test } 2^{\mathrm{b}}\end{array}$ & $\begin{array}{l}\text { Minimal detectable } \\
\text { change score }\end{array}$ & $\begin{array}{l}\text { Mean \& SD of differences } \\
\text { between Test } 1 \& \text { Test } 3^{b}\end{array}$ & $\begin{array}{l}\text { Minimal detectable } \\
\text { change score }\end{array}$ \\
\hline \multirow[t]{6}{*}{ Lordosis $^{c}$} & \multirow[t]{2}{*}{ Lumbar lordosis } & NoLBP & $-29.6 \pm 11.2$ & $-31.2 \pm 11.3$ & $-29.4 \pm 10.8$ & $-30.1 \pm 11.1$ & $1.5 \pm 6.9$ & \pm 11.3 & $-0.5 \pm 9.1$ & \pm 15.0 \\
\hline & & LBP & $-27.1 \pm 11.6$ & $-28.1 \pm 10.5$ & $-28.2 \pm 11.8$ & $-27.8 \pm 11.2$ & $1.0 \pm 5.4$ & \pm 8.8 & $0.2 \pm 9.0$ & \pm 14.8 \\
\hline & \multirow[t]{2}{*}{ Trunk angle } & NoLBP & $-9.9 \pm 5.7$ & $-10.5 \pm 5.1$ & $-11.0 \pm 4.2$ & $-10.4 \pm 5.0$ & $0.6 \pm 4.2$ & \pm 6.9 & $1.2 \pm 4.7$ & \pm 7.7 \\
\hline & & LBP & $-9.5 \pm 5.5$ & $-9.4 \pm 4.0$ & $-9.9 \pm 4.5$ & $-9.6 \pm 4.7$ & $0.0 \pm 3.7$ & \pm 6.1 & $0.3 \pm 3.4$ & \pm 5.6 \\
\hline & \multirow[t]{2}{*}{ Pelvic angle } & NoLBP & $19.7 \pm 10.0$ & $20.7 \pm 9.6$ & $18.4 \pm 9.6$ & $19.6 \pm 9.7$ & $-1.0 \pm 5.5$ & \pm 9.0 & $1.7 \pm 7.2$ & \pm 11.9 \\
\hline & & LBP & $17.6 \pm 9.3$ & $18.7 \pm 10.8$ & $18.4 \pm 10.4$ & $18.2 \pm 10.1$ & $-1.1 \pm 5.8$ & \pm 9.6 & $0.0 \pm 7.9$ & \pm 13.0 \\
\hline \multirow[t]{6}{*}{ Flexion $^{c}$} & \multirow[t]{2}{*}{ Trunk (T12) angle } & NoLBP & $104.9 \pm 15.4$ & $106.4 \pm 15.5$ & $105.8 \pm 15.7$ & $105.7 \pm 15.4$ & $-1.5 \pm 4.1$ & \pm 6.8 & $-0.4 \pm 5.7$ & \pm 9.3 \\
\hline & & LBP & $110.4 \pm 14.3$ & $110.2 \pm 13.2$ & $109.6 \pm 13.1$ & $110.1 \pm 13.4$ & $0.2 \pm 5.3$ & \pm 8.7 & $-0.4 \pm 6.2$ & \pm 10.2 \\
\hline & \multirow[t]{2}{*}{ Lumbar range } & NoLBP & $51.2 \pm 8.1$ & $54.1 \pm 8.9$ & $50.9 \pm 10.1$ & $52.1 \pm 9.1$ & $-2.9 \pm 6.6$ & \pm 10.8 & $-0.4 \pm 7.9$ & \pm 13.0 \\
\hline & & LBP & $49.9 \pm 11.6$ & $50.1 \pm 11.4$ & $50.5 \pm 11.5$ & $50.2 \pm 11.3$ & $-0.2 \pm 5.0$ & \pm 8.4 & $-0.2 \pm 8.4$ & \pm 14.0 \\
\hline & \multirow[t]{2}{*}{ Pelvic (S2) angle } & NoLBP & $54.9 \pm 15.3$ & $53.7 \pm 14.6$ & $55.8 \pm 15.5$ & $54.8 \pm 15.0^{d}$ & $1.2 \pm 5.0$ & \pm 8.2 & $0.2 \pm 6.6$ & \pm 10.9 \\
\hline & & LBP & $61.0 \pm 12.4$ & $60.0 \pm 14.4$ & $61.2 \pm 12.4$ & $60.8 \pm 13.2^{d}$ & $0.4 \pm 7.1$ & \pm 11.8 & $-1.0 \pm 9.9$ & \pm 16.6 \\
\hline \multirow[t]{6}{*}{ Extension ${ }^{c}$} & \multirow[t]{2}{*}{ Trunk angle } & NoLBP & $32.3 \pm 8.9$ & $32.3 \pm 9.5$ & $31.7 \pm 7.3$ & $32.1 \pm 8.6$ & $0.0 \pm 6.1$ & \pm 10 & $-0.6 \pm 6.0$ & \pm 9.9 \\
\hline & & LBP & $27.1 \pm 7.0$ & $26.2 \pm 7.6$ & $27.4 \pm 6.2$ & $26.9 \pm 7.0$ & $-0.9 \pm 3.9$ & \pm 6.3 & $1.0 \pm 4.4$ & \pm 7.2 \\
\hline & \multirow[t]{2}{*}{ Lumbar range } & NoLBP & $22.8 \pm 13.9$ & $22.3 \pm 12.2$ & $21.2 \pm 12.4$ & $22.1 \pm 12.8$ & $-0.5 \pm 7.6$ & \pm 12.5 & $-2.2 \pm 11.3$ & \pm 18.6 \\
\hline & & LBP & $15.1 \pm 8.5$ & $15.2 \pm 10.6$ & $15.6 \pm 7.2$ & $15.2 \pm 8.9$ & $0.1 \pm 5.5$ & \pm 9.0 & $1.4 \pm 3.8$ & \pm 6.2 \\
\hline & \multirow[t]{2}{*}{ Pelvic angle } & NoLBP & $11.3 \pm 8.5$ & $11.5 \pm 8.2$ & $12.7 \pm 9.3$ & $11.8 \pm 8.6$ & $0.2 \pm 5.9$ & \pm 9.7 & $1.8 \pm 8.4$ & \pm 13.8 \\
\hline & & LBP & $12.3 \pm 8.4$ & $11.3 \pm 9.7$ & $12.0 \pm 7.8$ & $11.9 \pm 8.7$ & $-1.1 \pm 6.2$ & \pm 10.1 & $-0.3 \pm 4.6$ & \pm 7.6 \\
\hline \multirow[t]{6}{*}{ Left lateral flexion ${ }^{c}$} & \multirow[t]{2}{*}{ Trunk angle } & NoLBP & $31.2 \pm 6.6$ & $30.7 \pm 6.0$ & $29.9 \pm 5.4$ & $-30.6 \pm 6$ & $-0.5 \pm 4.1$ & \pm 6.9 & $-0.8 \pm 4.9$ & \pm 8.1 \\
\hline & & LBP & $29.8 \pm 6.0$ & $31.1 \pm 6.5$ & $28.5 \pm 6.1$ & $-29.9 \pm 6.2$ & $1.3 \pm 3.9$ & \pm 6.5 & $-0.7 \pm 3.4$ & \pm 5.7 \\
\hline & \multirow[t]{2}{*}{ Lumbar range } & NoLBP & $24.1 \pm 4.7$ & $23.9 \pm 4.3$ & $23.3 \pm 4.6$ & $-23.8 \pm 4.5$ & $-0.2 \pm 3.3$ & \pm 5.5 & $-0.2 \pm 3.9$ & \pm 6.6 \\
\hline & & LBP & $24.3 \pm 5.3$ & $24.6 \pm 5.9$ & $23.1 \pm 5.9$ & $-24.1 \pm 5.7$ & $0.3 \pm 3.5$ & \pm 5.8 & $-1.1 \pm 3.2$ & \pm 5.3 \\
\hline & \multirow[t]{2}{*}{ Pelvic angle } & NoLBP & $7.3 \pm 4.1$ & $7.1 \pm 3.8$ & $6.9 \pm 3.6$ & $-7.4 \pm 3.8$ & $-0.2 \pm 2.5$ & \pm 4.2 & $-0.5 \pm 2.7$ & \pm 4.5 \\
\hline & & LBP & $5.7 \pm 2.8$ & $6.8 \pm 3.7$ & $5.5 \pm 3.5$ & $-6.0 \pm 3.4$ & $1.1 \pm 2.6$ & \pm 4.3 & $0.3 \pm 2.4$ & \pm 4.1 \\
\hline
\end{tabular}


Table 2 Lordosis and ROM scores, and consistency between tests (degrees) (Continued)

\begin{tabular}{|c|c|c|c|c|c|c|c|c|c|c|}
\hline \multirow{6}{*}{$\begin{array}{l}\text { Right lateral } \\
\text { flexionc }^{c}\end{array}$} & \multirow[t]{2}{*}{ Trunk angle } & NoLBP & $31.9 \pm 6.0$ & $32.4 \pm 6.5$ & $31.6 \pm 6.5$ & $32 \pm 6.2$ & $-0.5 \pm 2.9$ & \pm 4.9 & $-0.2 \pm 2.7$ & \pm 4.5 \\
\hline & & LBP & $29.5 \pm 5.1$ & $29.8 \pm 5.1$ & $26.5 \pm 5.7$ & $28.8 \pm 5.4$ & $-0.3 \pm 4.0$ & \pm 6.6 & $-2.6 \pm 3.5$ & \pm 5.8 \\
\hline & \multirow[t]{2}{*}{ Lumbar range } & NoLBP & $24.4 \pm 4.6$ & $24.9 \pm 4.5$ & $24.7 \pm 4.6$ & $24.7 \pm 4.5$ & $-0.5 \pm 2.4$ & \pm 4.0 & $-0.7 \pm 3.1$ & \pm 5.2 \\
\hline & & LBP & $23.2 \pm 5.2$ & $22.8 \pm 4.6$ & $21.3 \pm 5.7$ & $22.3 \pm 5.6$ & $0.4 \pm 3.0$ & \pm 5.1 & $1.9 \pm 2.6$ & \pm 4.3 \\
\hline & \multirow[t]{2}{*}{ Pelvic angle } & NoLBP & $7.7 \pm 3.9$ & $7.7 \pm 4.0$ & $7.1 \pm 3.8$ & $7.5 \pm 3.9$ & $0.0 \pm 2.5$ & \pm 4.1 & $0.6 \pm 2.7$ & \pm 4.5 \\
\hline & & LBP & $6.4 \pm 2.9$ & $7.1 \pm 3.3$ & $5.4 \pm 3.3$ & $6.4 \pm 3.2$ & $-0.7 \pm 3.1$ & \pm 5.1 & $0.7 \pm 2.8$ & \pm 4.8 \\
\hline
\end{tabular}

Legend: LBP LBP group, NoLBP no LBP group, ROM ROM

${ }^{a}$ ROM and standard deviation data represent the group mean and standard deviation (SD). The standard deviation indicates the magnitude of differences between individuals within the group

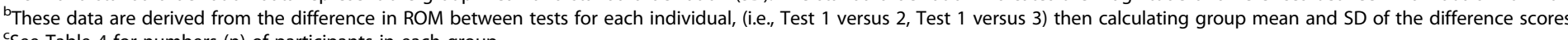

'See Table 4 for numbers ( $n$ ) of participants in each group

Indicates significant difference between groups 


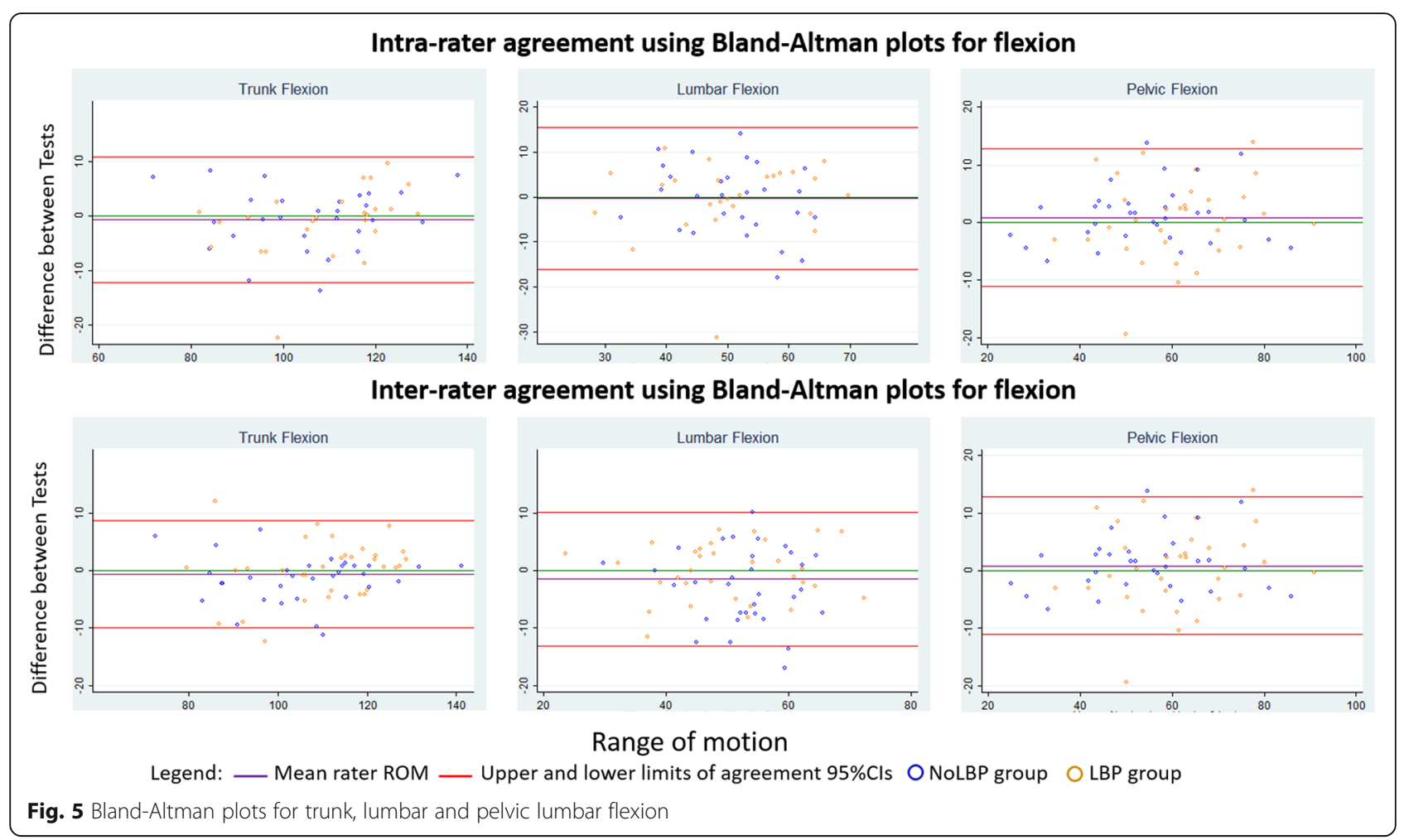

are required to be similarly sure of true change for extension (see Table 4).

\section{Inter-rater and intra-rater reliability}

ICCs (Table 4) across all measured characteristics averaged $r=.88$ (range .80 to .98 ) for same-day inter-rater reliability and $r=.85$ (range .67 to .97) for different-day intra-rater reliability. All ICCs were below $P=.005$. The results for both intra and inter rater agreement demonstrate good to excellent agreement for almost all comparisons [35].

\section{Discussion}

\section{Overview}

In this study, we assessed people with and without LBP and determined the consistency in measurements of their standing lordosis, active movement range and lumbopelvic rhythm over two tests on the same day and a third test 7-14 days later. We found that the LBP and NoLBP participants had similar standing lordosis angles and ROM, with the exception of greater pelvic ROM in flexion (LBP group), and greater trunk and lumbar ROM in right lateral flexion (NoLBP group). Although the LBP group demonstrated similar trunk ROM during flexion, this appeared to have been achieved through relatively greater pelvis/hip contribution. In addition, we found no significant difference in movement consistency between the NoLBP and LBP groups. Lastly, we found good to excellent inter-rater (same day) and intra-rater (different days) reliability for most movements, with $\mathrm{MDC}_{90}$ estimates for expected variation between tests in the order of $5-15^{\circ}$ and $\mathrm{MDC}_{90}$ estimates for lumbar contribution to lumbo-pelvic rhythm in flexion and lateral flexion that ranged from 8 to $15 \%$. In contrast, the $\mathrm{MDC}_{90}$ estimates for lumbar contributions to extension showed an expected variability that was in the order of 36-56\% and these findings may limit the clinical utility of monitoring changes in lumbar contribution to extension.

\section{ROM and variability comparisons}

A recent meta-analysis identified that, on average, people with chronic LBP have less lumbar ROM than people who do not have LBP [22]. Our data did not demonstrate any significant difference between groups in lumbar ROM, although there was a trend towards there being more hip and less lumbar spine involved in achieving flexion ROM for people with LBP (Fig. 4). In addition, we noted less lumbar extension in people with LBP although this also did not achieve significance. These observations warrant confirmation through studies of independent samples of people with and without LBP.

Clinical utility depends on how much change a clinician expects to see and knowledge of how much change is due to biological variation and measurement error. ROM data for all components (i.e., trunk, lumbar and pelvic ROM) of flexion and lateral flexion, and for extension (trunk ROM only) indicate sufficient stability to be potentially clinically 
Table 3 Lumbo-pelvic rhythm (expressed as the percentage of lumbar contribution to trunk ROM) and consistency between tests

\begin{tabular}{|c|c|c|c|c|c|c|c|c|c|}
\hline \multirow[t]{2}{*}{ Movement } & \multirow[t]{2}{*}{ Back pain status } & \multicolumn{4}{|c|}{ Average $\%$ Lumbar movement for each test ${ }^{a}$} & \multicolumn{2}{|c|}{ Inter-rater agreement (same-day, different raters) } & \multicolumn{2}{|c|}{ Intra-rater agreement (different-days, same rater) } \\
\hline & & Test 1 & Test 2 & Test 3 & $\begin{array}{l}\text { Average for } \\
\text { all } 3 \text { Tests }\end{array}$ & $\begin{array}{l}\text { Mean \& standard deviation of } \\
\text { differences }{ }^{\mathrm{b}} \text { between Test } 1 \\
\text { vs Test } 2\end{array}$ & $\begin{array}{l}\text { Minimal detectable } \\
\text { change }\left(\text { MDC }_{90}\right)\end{array}$ & $\begin{array}{l}\text { Mean \& standard deviation } \\
\text { of differences }{ }^{b} \text { between } \\
\text { Test } 1 \text { vs Test } 3\end{array}$ & $\begin{array}{l}\text { Minimal detectable } \\
\text { change (MDC } \text { (Mo) } \text { ) }\end{array}$ \\
\hline \multirow[t]{2}{*}{ Flexion $^{c}$} & NoLBP & $51.9 \% \pm 9.6 \%$ & $50.0 \% \pm 9.0 \%$ & $52.0 \% \pm 9.6 \%$ & $51.3 \% \pm 9.4 \%$ & $1.9 \% \pm 5.5 \%$ & $9.1 \%$ & $0.8 \% \pm 7.0 \%$ & $11.5 \%$ \\
\hline & LBP & $45.4 \% \pm 8.9 \%$ & $45.6 \% \pm 8.6 \%$ & $46.4 \% 10.7 \%$ & $45.8 \% \pm 8.6 \%$ & $0.2 \% \pm 5.9 \%$ & $8.5 \%$ & $0.5 \% \pm 9.4 \%$ & $15.5 \%$ \\
\hline \multirow[t]{2}{*}{ Extension $^{c}$} & NoLBP & $68.4 \% \pm 34.0 \%$ & $68.9 \% \pm 31.2 \%$ & $66.6 \% \pm 33.2 \%$ & $68.0 \% \pm 32.3 \%$ & $0.5 \% \pm 22 \%$ & $36.3 \%$ & $2.6 \% \pm 34.2 \%$ & $56.2 \%$ \\
\hline & LBP & $58.2 \% \pm 30.2 \%$ & $56.2 \% \pm 30.6 \%$ & $59.0 \% \pm 29.7 \%$ & $56.9 \% \pm 33.7 \%$ & $2.0 \% \pm 25.2 \%$ & $41.4 \%$ & $1.1 \% \pm 31.8 \%$ & $52.3 \%$ \\
\hline \multirow{2}{*}{$\begin{array}{l}\text { Left lateral } \\
\text { flexion }^{c}\end{array}$} & NoLBP & $78.5 \% \pm 10.0 \%$ & $78.7 \% \pm 9.0 \%$ & $79.0 \% \pm 9.8 \%$ & $78.6 \% \pm 9.5 \%$ & $0.2 \% \pm 7.3 \%$ & $12.0 \%$ & $0.6 \% \pm 7.2 \%$ & $11.8 \%$ \\
\hline & LBP & $81.6 \% \pm 8.2 \%$ & $79.2 \% \pm 10.2 \%$ & $81.1 \% \pm 10.4 \%$ & $80.6 \% \pm 9.6 \%$ & $2.4 \% \pm 7.3 \%$ & $12.0 \%$ & $1.6 \% \pm 7.2 \%$ & $11.8 \%$ \\
\hline \multirow{2}{*}{$\begin{array}{l}\text { Right } \\
\text { lateral } \\
\text { flexion }\end{array}$} & NoLBP & $77.4 \% \pm 9.5 \%$ & $78.2 \% \pm 8.8 \%$ & $79.3 \% \pm 8.3 \%$ & $78.0 \% \pm 9.1 \%$ & $0.7 \% \pm 6.8 \%$ & $11.2 \%$ & $2.3 \% \pm 6.3 \%$ & $10.4 \%$ \\
\hline & LBP & $78.4 \% \pm 9.4 \%$ & $76.6 \% \pm 9.4 \%$ & $80.2 \% \pm 11.6 \%$ & $78.3 \% \pm 10.0 \%$ & $1.8 \% \pm 8.2 \%$ & $13.5 \%$ & $1.0 \% \pm 8.9 \%$ & $14.6 \%$ \\
\hline
\end{tabular}

\section{aCalculated by dividing lumbar ROM over trunk ROM then converting to percentage}

${ }^{\mathrm{b}}$ See explanation in Table 3 footnote regarding methods used in calculating the SD of difference scores

cSee Table 4 for numbers ( $n$ ) of participants in each group 
Table 4 Inter-rater and Intra-rater reliability (Intraclass Correlation Coefficients using mean of repetitions 2-5)

\begin{tabular}{|c|c|c|c|c|c|c|c|c|}
\hline \multirow[t]{2}{*}{ Interrater } & \multicolumn{4}{|c|}{ NoLBP subjects } & \multicolumn{4}{|c|}{ LBP subjects } \\
\hline & $n=$ & T12 angle & Pelvic angle & Lumbar ROM & $n=$ & T12 angle & Pelvic angle & Lumbar ROM \\
\hline Flexion & 32 & .98 (.96 to .99) & .97 (.94 to .99$)$ & $.80(.56$ to .91$)$ & 32 & .96 (.92 to .98) & .92 (.84 to .96$)$ & .95 (.90 to .98$)$ \\
\hline Extension & 31 & .88 (.74 to .94$)$ & .87 (.72 to .93$)$ & $.91(.81$ to .96$)$ & 28 & .95 (.90 to .98$)$ & $.77(.52$ to .89$)$ & .94 (.87 to .97$)$ \\
\hline Lordosis & 33 & .83 (.65 to .91$)$ & .91 (.83 to .96$)$ & $.90(.79$ to .95$)$ & 32 & .83 (.65 to .92$)$ & .91 (.81 to .96$)$ & .94 (.87 to .97$)$ \\
\hline Lateral Flexion left & 33 & .88 (.76 to .94$)$ & .89 (.77 to .94$)$ & .84 (.68 to .92$)$ & 32 & .89 (.76 to .94$)$ & .79 (.56 to .90$)$ & .89 (.78 to .95$)$ \\
\hline Lateral flexion right & 33 & .94 (.88 to .97$)$ & .88 (.72 to .95$)$ & $.92(.84$ to .96$)$ & 32 & .82 (.64 to .91) & .67 (.33 to .83$)$ & .89 (.79 to .95$)$ \\
\hline Intrarater & \multicolumn{4}{|c|}{ NoLBP subjects } & \multicolumn{4}{|c|}{ LBP subjects } \\
\hline Flexion & 28 & .97 (.93 to .99$)$ & .95 (.90 to .98$)$ & .86 (.68 to .94) & 25 & .95 (.89 to .98$)$ & .86 (.69 to .94$)$ & .86 (.69 to .94$)$ \\
\hline Extension & 28 & .84 (.64 to .92$)$ & .71 (.38 to .86) & .79 (.54 to .90$)$ & 21 & .94 (.88 to .98$)$ & .67 (.25 to .86$)$ & .94 (.87 to .97$)$ \\
\hline Lordosis & 30 & .71 (.40 to .86$)$ & .84 (.68 to .93$)$ & .81 (.59 to .91$)$ & 25 & .89 (.74 to .95$)$ & .82 (.60 to .92$)$ & .85 (.65 to .93$)$ \\
\hline Lateral Flexion left & 30 & .77 (.53 to .89) & .85 (.69 to .93$)$ & .76 (.49 to .89$)$ & 25 & $.92(.82$ to .96$)$ & .83 (.61 to .92$)$ & .92 (.81 to .96$)$ \\
\hline Lateral flexion right & 30 & .95 (.90 to .98$)$ & .88 (.75 to .94$)$ & .89 (.77 to .95$)$ & 25 & .85 (.46 to .94$)$ & $.70(.34$ to .87$)$ & .92 (.68 to .97$)$ \\
\hline
\end{tabular}

Legend: ROM = ROM Intraclass correlation co-efficients (ICC 2,2) and $95 \%$ confidence intervals

useful with $\mathrm{MDC}_{90^{\prime} \mathrm{s}}$ of $5-15^{\circ}$ (flexion), 4-8 (lateral flexion) and $6-10^{\circ}$ (trunk extension) indicating high probability of true change. However, changes to lumbar and pelvic extension were associated with higher retest variations, with $\mathrm{MDC}_{90^{\prime}}$ of $10-14^{\circ}$ (pelvic movements) and up to $19^{\circ}$ (lumbar spine movements). These findings may limit the clinical utility of using changes in lumbar spine extension ROM to monitor progress.

Trunk angle measurements were generally associated with smaller retest variations than lumbar or pelvic angle measurements, which may inspire the argument that trunk ROM is the more sensitive and potentially valuable outcome measure. Our data indicate however that people with LBP appear to retain full flexion ROM by increasing pelvic/hip movement while limiting lumbar contribution.

Inter-rater (same day) differences between tests were generally smaller than intra-rater (different day) differences. This is a common finding in reliability studies and is likely to be due to a combination of factors that occur between measurement days, such as normal biological variations, minor variations to experimental conditions and possible environmental factors. We studied intra-rater different-day measurements as this reflects common clinical practice, making the results relevant to clinical decision-making.

\section{Within-test repeated movement consistency}

The first repetition of flexion and right lateral flexion movements was significantly different to subsequent repetitions, with similar, non-statistically significant, patterns seen for other movements (see Fig. 4). As a consequence, we used repetitions 2-5 for analysis of movement consistency. This renders the study results relevant to clinicians who allow clients to practice the test before commencing measurement. The first repetition of a test may be affected by apprehension, uncertainty about what is required, fear of pain, movement stiffness, and distraction or inattention, to name only some of the possible factors that might explain this aspect of our data.

\section{Lordosis}

Lumbar lordosis angles are of clinical interest in assessing spinal alignment and postural archetypes. A wide range of group mean lordosis angles, measured by skin surface techniques, have been reported. A recent review of nine studies reported mean lordosis angles ranging from $23^{\circ}$ to $55^{\circ}$ [22]. Mean $( \pm \mathrm{SD})$ standing lordosis, measured in this study, ranged from $27^{\circ}$ to $31^{\circ} \pm 11^{\circ}$, without any significant differences between LBP and NoLBP groups. In our data, relatively large variability in standing lordosis angles was seen between tests on both the same day and on different days with $\mathrm{MDC}_{90}$ scores ranging from $9^{\circ}$ to $11^{\circ}$ for tests on the same day and up to $15^{\circ}$ for tests on different days. This variability may be a test artifact related to precision in sensor placement or it may be true biological variability. We were very particular in attempting precise sensor repositioning in repeated tests and it is unlikely that greater accuracy in sensor placement would be expected in typical clinical practice.

\section{Lumbo-pelvic rhythm}

Various patterns of lumbo-pelvic movement have been described but few patterns have been measured or reported as outcomes. Clinicians are interested in identifying the contributions to trunk movement from hip movement and lumbar spine movement. It has been proposed that when extremes of lumbar or pelvic contribution to trunk flexion are corrected, associated pain can be reduced $[10,11]$. This study showed relatively greater hip compared to lumbar contribution for the LBP group. We 
Laird et al. BMC Musculoskeletal Disorders (2016) 17:403

Page 12 of 14

speculate that this maybe a compensatory mechanism as a response to reduced lumbar ROM. A recent meta-analysis (six studies) of typical lumbo-pelvic rhythm showed similar but nonsignificant findings of reduced lumbar contribution to trunk flexion [22]. Although lumbo-pelvic rhythm has been reported using a lumbar/pelvic angle ratio, we consider that percentage lumbar contributions to trunk movement are easier to visualise and circumvent the complexities associated with interpretation of ratios (that can be affected by both the numerator and the denominator). If trunk movement occurs entirely at the lumbar spine, the lumbo-pelvic rhythm will be $100 \%$, while a person who bends with the pelvis/hips and without lumbar spine movement will score $0 \%$.
In our data (Table 3), mean lumbar contribution to trunk flexion ranged from $46 \% \pm 9 \%$ to $51 \% \pm 9 \%$. This is closely consistent with Kim et al. [15] who reported similar mean lumbar contributions to trunk flexion of $45 \% \pm 9 \%$ to $49 \% \pm 9 \%$.

Considerable test-to-test variability in the percentage contribution of pelvic and lumbar movement to trunk flexion was seen in our data for a small number of participants. An example of this variable motor control of lumbar and pelvic movement contribution, while maintaining relatively consistent trunk ROM, is shown in Fig. 6. This NoLBP participant demonstrated an increase in lumbar contribution to trunk flexion from an initial 38 to $74 \%$, despite little difference in overall trunk ROM of around $80^{\circ}$.

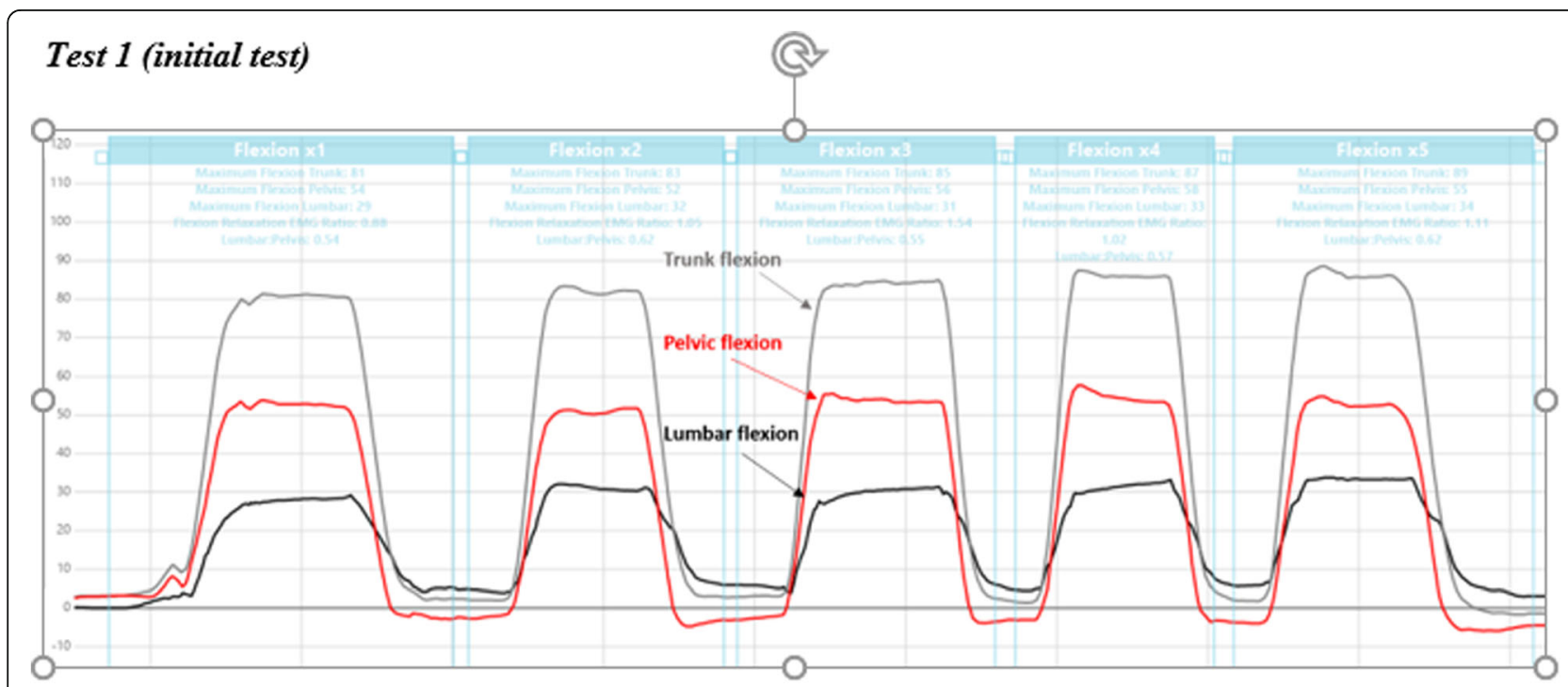

Test 3 (2 weeks later)

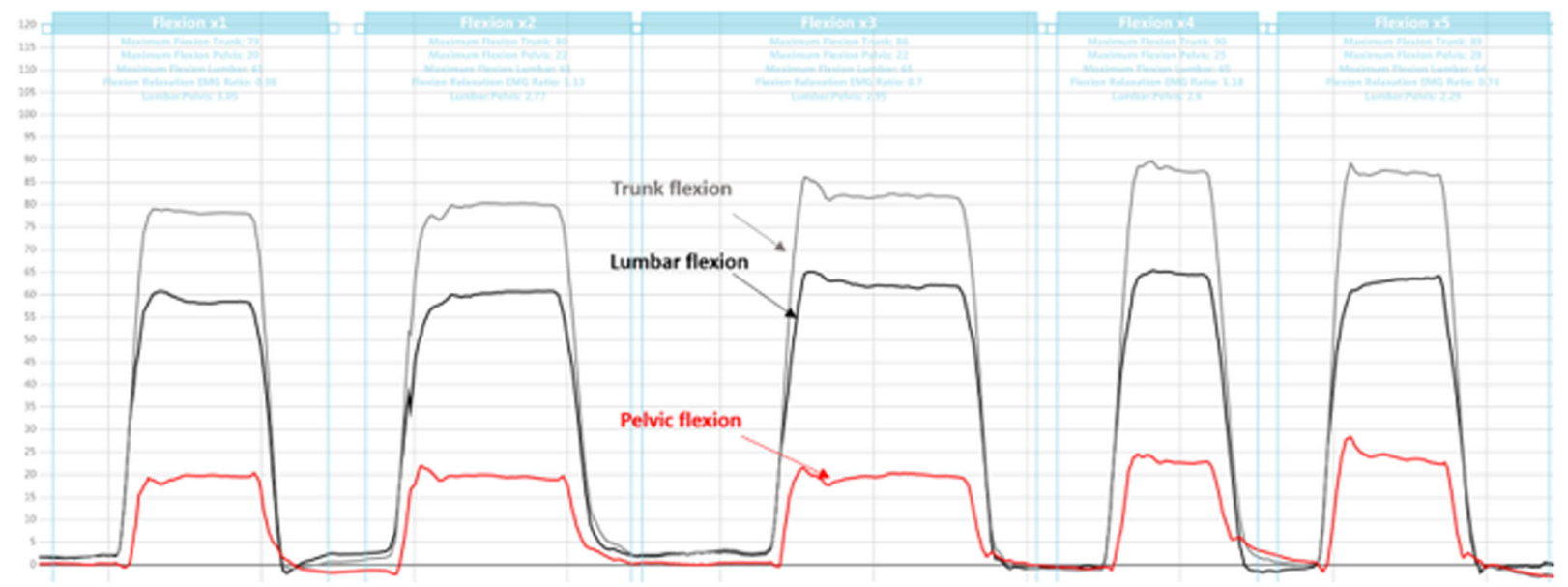

Fig. 6 Flexion lumbo-pelvic rhythm differences on Test 1 versus Test 3 (two weeks apart) for participant No. 71 (NoLBP). Illustrates differences between days for flexion and lumbo-pelvic rhythm in one participant. Grey line = trunk flexion, black line = lumbar flexion and the red line $=$ pelvic (hip) flexion 


\section{Limitations of this study}

Using a skin surface measurement technique to measure movement has the advantage of being non-invasive and possible within a typical clinical setting. However, any skin surface measurement technique has to be vigilant for artefacts that can occur due to issues such as skin buckling, sensor placement error, loss of sensor adherence to skin, etc. Excessive adipose tissue and skin buckling can alter the orientation of the surface-mounted movement sensor in some people, although simple observation can screen for this type of error. Skin surface measurement also has the inherent issue of sensor placement error, with relatively poor reliability of manual palpation of bony landmarks [30]. However we attempted to reduce this error by additional linear measurement to reduce placement error for subsequent tests.

There is a significant difference between LBP and NoLBP groups for age, with the LBP group being older on average. Other studies have shown that ROM diminishes with age but these changes are more visible in the 5th and 6th decades [36]. While it is possible that age-related differences between groups may account for reduced movement in the LBP group (trunk and lumbar right lateral flexion), it is unlikely age would explain increased ROM (pelvic flexion) or the altered lumbo-pelvic rhythm (where trunk ROM was the similar for both groups).. A significant difference for activity limitation was seen between Test 1 versus Test 3 for the LBP group but the difference between scores was 1.5 on the RMDQ and is unlikely to be clinically meaningful.

Rotational measurements were not technically possible with motion sensors at the time of testing but advances now allow for testing axial rotation. Further research should include rotation.

This study was not powered to test for differences between subgroups within the LBP population (pain intensity, presence of leg pain, mechanism of injury, movement pattern, aggravating activities etc.) so it possible that various subgroup definitions may demonstrate different results.

We conducted multiple ANOVAs when studying the differences in ROM for those with and without LBP, and retained our alpha level at .05 for all comparisons. Some observed differences between groups may therefore be chance findings, and the study findings warrant testing in independent studies.

A further limitation may be the single intra-rater comparison. Further studies could include multiple intra-rater comparisons to increase the robustness of extrapolating these results to other clinicians.

\section{Conclusion}

This study compared the consistency of lumbar lordosis, lumbo-pelvic range of movement (ROM) and lumbo-pelvic rhythm in people with and without low back pain, over three test sessions: two tests on the same day and a third test, 1 to 2 weeks later. There was little difference between the LBP and NoLBP groups for lordosis angle, and most ROM conditions, with the exception of greater pelvic flexion and reduced trunk and lumbar right lateral flexion ROM. Significantly reduced relative lumbar contribution to flexion lumbo-pelvic rhythm was seen in the LBP group. Movement consistency between each test was described by using $\mathrm{MDC}_{90}$ to measure between-test differences. Mean lumbar lordosis angles of approximately $30^{\circ}$ required around $10^{\circ}$ change to have $90 \%$ confidence of seeing true change between same-day tests and $15^{\circ}$ for different-day tests. ROM tests showed relatively greater consistency with changes ranging from 5 to $15^{\circ}$ between tests required to similarly identify true change. Lumbo-pelvic rhythm changes of $>8-15 \%$ lumbar contribution to flexion and lateral flexion trunk ROM indicated probable change, while a larger change of $>36-56 \%$ would be needed to be confident of change to an extension lumbo-pelvic rhythm.

\section{Additional file}

Additional file 1: Description and details of measured lumbo-pelvic kinematics. Description of data: Provides information about movements tested, sensor placement and instruction to the subject. (DOCX 12 kb)

\section{Abbreviations}

LBP: Low back pain; NoLBP: Participants without low back pain;

RMDQ: Roland Morris Disability Questionnaire; ROM: ROM

\section{Acknowledgements}

Sincere thanks to Todd Scarce, physiotherapist, for assistance with data collection.

\section{Funding}

No funding was received for this study.

Availability of data and materials

All raw data and information related to additional files can be obtained from the first author at robert.laird@monash.edu. All patient data has been de-identified.

\section{Authors' contributions}

$\mathrm{RL}$ contributed to data collection. $\mathrm{RL}$ was the main author of this paper, with concept, writing, data analysis, interpretation, draft revision and gave approval of the final manuscript. JK provided concept guidance, statistical direction, analysis, draft revision and gave approval of the final manuscript. PK provided concept guidance, statistical analysis, draft revision and gave approval of the final manuscript. RL, JK and PK agree to be accountable for all aspects of the work in ensuring that questions related to the accuracy or integrity of any part of the work are appropriately investigated and resolved.

\section{Competing interests}

No benefits in any form have been, or will be, received for this study from a commercial party related directly or indirectly to the subject of this paper. This paper does not contain information about drugs. The authors do not hold stocks or shares in any company that might be directly or indirectly affected by this study. No patents have been applied for or received due to the content of this paper and there are no non-financial competing interests associated with this paper. 
The lead author (RL) has been engaged as a consultant by DorsaVi for training clinicians in how to use the ViMove device but otherwise has no financial interest in the company, DorsaVi, nor has received any funding for this study. PK has received a market-rate consulting fee from DorsaVi for clinical trial design advice unrelated to the current study but otherwise has no financial interest in the company, DorsaVi.

\section{Consent for publication}

Not applicable.

\section{Ethics approval and consent to participate}

Ethics approval was obtained from Monash University Human Research Ethics Committee (approval number CF12/1995-20 12001090). All participants gave written informed consent for testing and use of de-identified data, through the use of an ethics committee approved patient information and consent form.

\section{Author details}

'Department of Physiotherapy, Monash University, PO Box 527, Frankston, VIC 3199, Australia. ${ }^{2}$ School of Physiotherapy and Exercise Science, Curtin University, Perth, Australia. ${ }^{3}$ Department of Sports Science and Clinical Biomechanics, University of Southern Denmark, Odense, Denmark. ${ }^{4} 380$ Springvale Rd, Forest Hill, 3131 Melbourne, VIC, Australia.

\section{Received: 11 March 2016 Accepted: 10 September 2016}

\section{Published online: 22 September 2016}

\section{References}

1. Vos T, Flaxman AD, Naghavi M, Lozano R, Michaud C, Ezzati M, Shibuya K, Salomon JA, Abdalla S, Aboyans V, et al. Years lived with disability (YLDs) for 1160 sequelae of 289 diseases and injuries 1990-2010: a systematic analysis for the Global Burden of Disease Study 2010. Lancet. 2012;380(9859):2163-96.

2. Pincus T, Kent P, Bronfort G, Loisel P, Pransky G, Hartvigsen J. Twenty-five years with the biopsychosocial model of low back pain - is it time to celebrate? A report from the Odense Forum XII. Spine. 2013;38(24):2118-23.

3. Lariviere C, Gagnon D, Loisel P. The effect of load on the coordination of the trunk for subjects with and without chronic low back pain during flexion-extension and lateral bending tasks. Clin Biomech. 2000;15(6):407-16.

4. Tafazzol A, Arjmand N, Shirazi-Adl A, Parnianpour M. Lumbopelvic rhythm during forward and backward sagittal trunk rotations: combined in vivo measurement with inertial tracking device and biomechanical modeling Clin Biomech. 2014;29:7+.

5. Esola MA, McClure PW, Fitzgerald GK, Siegler S. Analysis of lumbar spine and hip motion during forward bending in subjects with and without a history of low back pain. Spine. 1996;21(1):71-8.

6. Lee RYW, Wong TKT. Relationship between the movements of the lumbar spine and hip. Hum Mov Sci. 2002;21(4):481-94.

7. McClure PW, Esola M, Schreier R, Siegler S. Kinematic analysis of lumbar and hip motion while rising from a forward, flexed position in patients with and without a history of low back pain. Spine. 1997;22(5):552-8.

8. Paquet N, Malouin F, Richards C. Hip-spine movement interaction and muscle activation patterns during sagittal trunk movements in low back pain patients. Spine. 1994;15(5):596-603.

9. Porter JL, Wilkinson A. Lumbar-hip flexion motion. A comparative study between asymptomatic and chronic low back pain in 18- to 36-year-old men. Spine. 1997;22(13):1508-13. discussion 1513-1504.

10. O'Sullivan P. Diagnosis and classification of chronic low back pain disorders: maladaptive movement and motor control impairments as underlying mechanism. Man Ther. 2005:10(4):242-55.

11. Sahrmann S. Diagnosis and treatment of movement impairment syndromes. 2002.

12. Van Dillen LR, Sahrmann SA, Norton BJ, Caldwell CA, McDonnell MK, Bloom N, Van Dillen LR, Sahrmann SA, Norton BJ, Caldwell CA, et al. The effect of modifying patient-preferred spinal movement and alignment during symptom testing in patients with low back pain: a preliminary report. Arch Phys Med Rehabil. 2003:84(3):313-22.

13. Ikeda K, McGill S. Can altering motions, postures, and loads provide immediate low back pain relief: a study of 4 cases investigating spine load, posture, and stability. Spine. 2012;37(23):E1469-75.

14. Pynt J, Mackey MG, Higgs J. Kyphosed seated postures: extending concepts of postural health beyond the office. J Occup Rehabil. 2008;18(1):35-45.
15. Kim MH, Yi CH, Kwon OY, Cho SH, Cynn HS, Kim YH, Hwang SH, Choi BR, Hong JA, Jung DH. Comparison of lumbopelvic rhythm and flexionrelaxation response between 2 different low back pain subtypes. Spine. 2013:38(15):1260-7.

16. Hodges PW, Coppieters MW, MacDonald D, Cholewicki J. New insight into motor adaptation to pain revealed by a combination of modelling and empirical approaches. Eur J Pain. 2013;17(8):1138-46.

17. Neblett R, Mayer TG, Brede E, Gatchel RJ. Correcting abnormal flexionrelaxation in chronic lumbar pain: responsiveness to a new biofeedback training protocol. Clin J Pain. 2010;26(5):403-9.

18. Brumagne $S$, Cordo P, Lysens R, Verschueren S, Swinnen S. The role of paraspinal muscle spindles in lumbosacral position sense in individuals with and without low back pain. Spine. 2000;25(8):989-94.

19. Descarreaux M, Blouin J-S, Teasdale N. Repositioning accuracy and movement parameters in low back pain subjects and healthy control subjects. Eur Spine J. 2005;14(2):185-91.

20. Kent $P$, Laird $R$, Haines $T$. The effect of changing movement and posture using motion-sensor biofeedback, versus guidelines-based care, on the clinical outcomes of people with sub-acute or chronic low back pain-a multicentre, cluster-randomised, placebo-controlled, pilot trial. BMC Musculoskelet Disord. 2015;16:131-50.

21. Long A, Donelson R, Fung T. Does it matter which exercise? A randomized control trial of exercise for low back pain. Spine. 2004;29(23):2593-602.

22. Laird R, Gilbert J, Kent P, Keating J. Comparing lumbo-pelvic kinematics in people with and without back pain: a systematic review and meta-analysis. BMC Musculoskelet Disord. 2014;15(1):229.

23. Laird R, Kent P, Keating J. Modifying patterns of movement in people with low back pain - does it help? A systematic review. BMC Musculoskelet Disord. 2012;13:169.

24. O'Sullivan KJ, O'Sullivan L, Campbell A, O'Sullivan P, Dankaerts W. Towards monitoring lumbo-pelvic posture in real-life situations: concurrent validity of a novel posture monitor and a traditional laboratory-ased motion analysis system. Man Ther. 2012;17:77-83.

25. Ribeiro DC, Sole G, Abbott JH, Milosavljevic S. Cumulative postural exposure measured by a novel device: a preliminary study. Ergonomics. 2011;54(9):858-65.

26. Bauer CM, Baumgartner L, Schelldorfer S, Ernst M, Lawrence M. Technical validation of a new movement therapy system for treatment of low back pain. Gait Posture. 2012;36:S40.

27. Ha TH, Saber-Sheikh K, Moore AP, Jones MP. Measurement of lumbar spine range of movement and coupled motion using inertial sensors - A protocol validity study. Man Ther 2013;18(1):87-91.

28. Manniche C, Asmussen K, Lauritsen B, Vinterberg H, Kreiner S, Jordan A. Low back pain rating scale: validation of a tool for assessment of low back pain. Pain. 1994;57(3):317-26.

29. Charry E, Umer M, Taylor S. Design and validation of an ambulatory inertial system for 3-D measurements of low back movements. Proceedings of Seventh International Conference on Intelligent Sensors, Sensor Networks and Information Processing (ISSNIP 2011) IEEE Conference Publications (http://ieeexplore.ieee.org/document/6146618/). Accessed 2016.

30. Kilby J, Heneghan NR, Maybury M. Manual palpation of lumbo-pelvic landmarks: a validity study. Man Ther. 2012;17(3):259-62.

31. Chien CW, Bagraith KS, Khan A, et al. Comparative responsiveness of verbal and numerical rating scales to measure pain intensity in patients with chronic pain. J Pain. 2013;14:1653-62.

32. Roland M, Fairbank J. The Roland-Morris disability questionnaire and the oswestry disability questionnaire. Spine. 2000;25(24):3115-24.

33. StataCorp. Stata Statistical Software: Release 12. College Station: StataCorp LP; 2011.

34. Mokkink LB, Terwee CB, Patrick DL, Alonso J, Stratford PW, Knol DL, Bouter LM, de Vet HCW. The COSMIN study reached international consensus on taxonomy, terminology, and definitions of measurement properties for healthrelated patient-reported outcomes. J Clin Epidemiol. 2010;63(7):737-45.

35. Portney $L G$, Watkins MP. Foundations of clinical research: applications to practice. 3rd ed. New Jersey: Pearson Prentice Hall; 2009.

36. Intolo P, Milosavljevic S, Baxter DG, Carman AB, Pal P, Munn J, Intolo P, Milosavljevic $\mathrm{S}$, Baxter DG, Carman AB, et al. The effect of age on lumbar range of motion: a systematic review. Man Ther. 2009;14(6):596-604. 